\title{
Nurses' practice concerning weaning from mechanical ventilation in the intensive care unit
}

\author{
M Borkowska ${ }^{1 *}$, S Labeau², S Blot ${ }^{1}$ \\ From ESICM LIVES 2015 \\ Berlin, Germany. 3-7 October 2015
}

\section{Introduction}

Weaning from mechanical ventilation is an important responsibility for ICU nurses [1].

\section{Objectives}

To identify weaning practices among ICU nurses.

\section{Methods}

A cross-sectional, self-administrated survey was developed. Consensus on content validity was achieved through a Delphi procedure among experts. The survey was distributed and collected during the annual congress of the Flemish Society of Critical Care Nurses (Dec. 2014).

\section{Results}

423 attendants completed the survey (response rate: 66\%) of which 342 ICU nurses were included for further analysis. These are employed in general (73\%) or university hospitals (27\%) and are working in mixed (66\%), surgical $(18 \%)$ or medical (13\%) ICUs.

Nurses working in university hospitals reported higher availability of weaning protocols $(44 \%$ vs $29 \%$; $p=0.016)$. $22 \%$ of nurses reported the availability of both weaning and sedation protocol. Protocols are paper-based (23\%) or computer-assisted (5\%) and in $20 \%$ of the cases never used. Nearly $20 \%$ of the nurses got some information or training about use of their protocol.

Most frequently chosen weaning modes are CPAP (77\%), BiLevel/BIPAP (74\%) and PSV (59\%). Nurses report to autonomously change ventilation modes (68\%), pressure support (PS) level (66\%) and respiratory rate (49\%). Before starting a spontaneous breathing trial (SBT) evaluation of respiratory status (83\%), respiratory capacity (73\%) and oxygenation $(63 \%)$ are considered. Spontaneous breathing on T-tube (58\%) is the most frequently chosen SBT approach next to CPAP (57\%) and PS ventilation with minimal PS (46\%). Duration of first SBT between 30 and 120 minutes was found in nearly $50 \%$ of responses but it was not associated with the presence or absence of a weaning protocol $(p=0.57)$. Less than 30 minutes SBT was reported by $45 \%$ of nurses. In majority of the cases is SBT repeated 3 times per day (38\%) and mostly at the daytime ( $99 \%$ vs. $37 \%)$.

SBT is considered successful if adequate gas exchange is maintained during the procedure $(89 \%)$, and prematurely terminated in case of signs of exhaustion (89\%), inadequacy of gas exchange (90\%) or hemodynamic instability (66\%). Prior to extubation almost all nurses (94\%) indicate oxygenation as an important parameter.

When it comes to weaning, nurses are generally satisfied about the cooperation with MDs. Decision making in weaning is mostly taken by MDs (91\%).

\section{Conclusions}

Less than half of nurses use weaning protocols. Variability in nurses' practical approaches to weaning appears to be considerable. Physicians are mostly involved in decision making on weaning.

\section{Authors' details}

${ }^{1}$ Ghent University, Ghent, Belgium. ${ }^{2}$ University College Ghent, Ghent, Belgium.

Published: 1 October 2015

\section{Reference}

1. Grap MJ, Munro CL, Ashtiani B, Bryant S: Oral care interventions in critical care: frequency and documentation. Am J Crit Care 2003, 12(2):113-118.

\section{doi:10.1186/2197-425X-3-S1-A561}

Cite this article as: Borkowska et al:: Nurses' practice concerning weaning from mechanical ventilation in the intensive care unit. Intensive Care Medicine Experimental 2015 3(Suppl 1):A561. 